\title{
Cultura in vitro de embrióes e de gemas de mudas de pau-rosa (Aniba rosaeodora Ducke).
}

\author{
Lucia HANDA ${ }^{1}$, Paulo de Tarso B. SAMPAIO ${ }^{2}$, Regina Caetano QUISEN $^{3}$
}

\begin{abstract}
RESUMO
Este trabalho teve como objetivo o estabelecimento in vitro de embrióes e de gemas de mudas de pau-rosa (Aniba rosaeodora Ducke) livres de contaminações e de oxidação fenólica. As gemas foram obtidas da rebrota de mudas cultivadas em viveiro e os embriões a partir de sementes em diversos estágios de maturação. Para a assepsia dos explantes foram utilizados dois antibiótico (Ampicilina e Agrimicina), etanol (70\%) e hipoclorito de sódio, em concentrações e tempo de exposição variando em função do tratamento. Para o controle da oxidação foram utilizados imersão em ácido ascórbico ( $250 \mathrm{mg} /$ ) e PVP (Polivinilpirrolidona) no meio Murashige \& Skoog (MS). O delineamento estatístico empregado foi o inteiramente ao acaso com tratamentos e repetições em função do tipo de explante. Foi observado $71 \%$ de sobrevivência e $53 \%$ de germinação de embriões tratados com hipoclorito de sódio ( $50 \%$ e $2 \%$ de cloro ativo) por 10 minutos e inoculados em meio MS contendo $20 \mathrm{mg} /$ de água de côco após 45 dias. As gemas das rebrotas de mudas tratadas com solução de Sulfato de Estreptomicina (Agrimicina) na concentração de $500 \mathrm{mg} /$ (1h) apresentaram $51 \%$ de sobrevivência. Quando submetidas ao pré-tratamento com o emprego de bomba a vácuo $(180 \mathrm{mmHg})$ contendo a Agrimicina ( $500 \mathrm{mg} /$ ), apresentaram $25 \%$ de sobrevivência.
\end{abstract}

\section{PALAVRAS-CHAVE}

Pau-rosa, Cultura de tecidos, Embriões, Rebrota

\section{Culture in vitro of rosewood (Aniba rosaeodora Ducke) embryos'seeds and buds explants.}

\begin{abstract}
This study deals with the establishment in vitro of Aniba rosaeodora Ducke explants, free from fungical and endogenous contaminations and phenolic oxidation. Bud explants and embryos' seeds from many maturation stages were used in this trial. The explants were disinfected with Ampicilin antibiotic, Streptomicine Sulphate (Agrimicina), etanol (70\%), sodium hipoclorite in many concentrations and exposure time acording to the type of explant. For the phenolic oxidation control, the immersion on ascorbic acid and PVP (Polyvinilpirrolidone) in culture medium were used. The explants were inoculated in MS medium. The statistical design was the completely randomized and the treatments and repetitions varied according to the type of explant adopted. After 45 days, 100\% of survival and 53\% of germination in embryos were observed, which had been desinfested by sodium bipoclorite (50\%) for 10 minutes and inoculated in MS medium, supplemented with 20 ml of coconut water. Satisfactory results (51\% of survival) were observed in bud's explants, which had been treated by immersion in $300 \mathrm{mg}^{l^{1}}$ of Agrimicina and $25 \%$ when submitted in $500 \mathrm{mg} . l^{-1}$ on vacuum pre-treatment.
\end{abstract}

\section{KEYWORDS}

rosewood, Aniba rosaeodora Ducke, tissue culture, embryoculture, buds

\footnotetext{
${ }^{1}$ Eng ${ }^{a}$ Florestal, M.Sc., INPA/UA, Manaus, AM, Brasil, lhanda@bol.com.br

${ }^{2}$ Eng ${ }^{\circ}$ Florestal, Dr., Pesquisador INPA/CPST, Manaus, AM, Brasil, sampaio@inpa.gov.br

${ }^{3}$ Eng ${ }^{\text {a }}$ Florestal, M.Sc., Embrapa Amazônia Ocidental, Manaus, AM, Brasil, rquisen@cpaa.embrapa.br
} 


\section{ACTA \\ AMAZONICA}

CULTURA IN VITRO DE EMBRIÕES E DE GEMAS

DE MUDAS DE PAU-ROSA (ANIBA ROSAEODORA DUCKE).

\section{INTRODUÇÃO}

O pau-rosa (Aniba rosaeodora Ducke) é uma espécie de notável valor econômico, devido o potencial econômico do óleo obtido por destilação das folhas, galhos, madeira e raízes, produto com grande demanda no mercado nacional e internacional devido ao seu uso como fixador na indústria de perfumes.

O corte indiscriminado de todos os indivíduos adultos em idade de reprodução além de causar a erosão genética, impossibilitou a regeneração natural, causando uma drástica redução das populações naturais, fato que levou o IBAMA a incluí-la na lista de espécies ameaçadas de extinção.

Estudos indicam que a propagação do pau-rosa é viável por sementes (Araújo, 1967; Rosa et al., 1993), estacas (Sampaio, 1988) e por mudas de regeneração natural (Alencar \& Araújo, 1980; Sampaio et al., 2000). Entretanto, a baixa e irregular produção de sementes aliado a elevada predação por pássaros, insetos e roedores, tem limitando a produção de mudas visando a recomposição das populações naturais e os plantios ex-situ (Ohashi et al., 1995). O desenvolvimento de técnicas de reprodução, a exemplo da cultura de tecidos, constitui-se numa alternativa de reprodução de genótipos superiores.

A cultura de tecidos consiste num conjunto de técnicas nas quais um explante é isolado e cultivado sob condições de plena assepsia, em um meio nutritivo artificial (Cestari, 1975; Hartman \& Kester, 1990; FAO, 1993; Pasqual et al., 1998). Assim, diversas partes da planta como gemas, meristemas apicais, embriões, segmentos de caule, extremidade de raízes e outras, podem ser cultivadas in vitro em meio nutritivo apropriado em ambiente asséptico (Grattapaglia \& Machado, 1998).

Por estarem alojados em ambiente asséptico dentro da semente, os embrióes são considerados fontes de explante que apresentam baixos índices de contaminação (Pierik, 1997; Hu \& Ferreira, 1998). Por meio do cultivo in vitro pode-se determinar as necessidades nutricionais e fisiológicas dos embriões; superar a dormência em certos tipos de sementes em virtude da imaturidade do embrião ou da presença de substâncias inibidoras no endosperma e obter fonte de explantes com tecido de elevada totipotência (Henao, 1991; Pierik, 1997; Hu \& Ferreira, 1998).

Alguns fatores são levados em consideração na cultura de embriões, como escolha do meio adequado, utilização dos reguladores de crescimento, a liberação de compostos fenólicos, estágio de desenvolvimento do embrião e condições da planta matriz (Pierik, 1997; Andrade, 1998 ; Pasqual et al., 1998).

Dependendo do seu crescimento e desenvolvimento, as exigências nutricionais são diferenciadas para promover o crescimento in vitro dos embriões (Pasqual \& Pinto, 1988; Ribeiro et al., 1997). Embriões imaturos necessitam de 8 a 12\% de sacarose, sais minerais e vitaminas (Pasqual \& Pinto, 1988; Henao, 1991), enquanto os embrióes maduros requerem de 2 a 3\% de sacarose, germinam e crescem em meio inorgânico (Hu \& Ferreira, 1998; Pierik, 1997). As maiores concentrações de sacarose para embriões imaturos deve-se às características heterotróficas destes, enquanto que os embriões maduros são quase autotróficos (Hu \& Ferreira, 1998).
A água de côco pode ser usada como suplementação do meio de cultura, fornecendo açúcares e outros glicídios, aminoácidos e suas amidas, fitormônios e outros metabólitos, como forma de suprir as exigências nutricionais dos embriões, em especial, os imaturos (Henao, 1991; Roca \& Mroginski, 1991; Hu \& Ferreira, 1998). O uso de reguladores de crescimento associados com a ausência de luz (escuro por 15 dias ) e temperatura entre 22 a $28^{\circ} \mathrm{C}$ aceleram o processo de desenvolvimento dos embriões e evitam a oxidação (Pierik, 1997; Hu \& Ferreira, 1998).

Em diversas espécies florestais tem-se obtido resultados que indicam a possibilidade de obtenção, num curto espaço de tempo, de grandes quantidades de novas plantas a partir de um único explante em subcultivos periódicos. A propagação in vitro do pau-rosa torna-se uma alternativa para conservação e utilização do potencial econômico desta espécie, por meio da multiplicação de genótipos selecionados, disponibilizando ao produtor mudas para plantios ex-situ e enriquecimento de florestas nativas.

O presente trabalho teve como objetivo avaliar técnicas de assepsia de embriões e gemas apicais de mudas de pau-rosa cultivadas in vitro.

\section{MATERIAL E MÉTODOS}

Os embriões retirados das sementes em diversos estágios de maturação, foram imersos por uma noite em Benomyl (300 $\mathrm{mg} / \mathrm{l})$. Na câmara de fluxo laminar, foram imersos em etanol (70\%) acrescido de Tween-20 por um minuto e trinta segundos, seguido de hipoclorito de sódio (50\%) por 10 minutos, seguidos das três lavagens em água destilada e autoclavada. A seguir foram inoculados em tubos de ensaio contendo meio de Murashige \& Skoog (1962), com pH ajustado em 6,2 e adição de $0,5 \mathrm{~g} / \mathrm{l}$ de antioxidante PVP (Polivinilpirrolidona), $1,8 \mathrm{~g} / \mathrm{de}$ fitagel, água de côco $(0,10,20 \mathrm{ml})$ e sacarose $(0,5,10$ e $15 \%)$ para estimular a germinação. O experimento contou com 12 tratamentos, com 10 repetições por tratamento. Os dados foram submetidos a análise de variância e comparação de média dos tratamentos pelo teste de Tukey.

Os experimentos foram instalados no Laboratório de Biotecnologia Vegetal da Embrapa Amazônia Ocidental, localizado no Km 29 da Rodovia AM-010, Manaus, AM.

As gemas axilares e terminais foram obtidas das rebrotas das mudas cultivadas em casa de vegetação da Embrapa Amazônia Ocidental. No período de 180 dias que antecederam a instalação dos experimentos in vitro, a cada 15 dias as mudas foram tratadas com fungicida Benlate 500 (metil-1 (butilcarbomil)-2-benzimidazol carbamato) na concentração de $3 \mathrm{~g} /$. A cada três meses foram realizadas adubações de NPK na proporção de 1:2:1.

No primeiro experimento, o pré-tratamento foi realizado a partir da imersão das gemas em Benomyl $(400 \mathrm{mg} /)$ por 12 horas. Na seqüência, foram imersos em Agrimicina $(0,300,400$ e $500 \mathrm{mg} / \mathrm{l}$ ), etanol (70\%) com Tween-20 por 90 segundos e em hipoclorito de sódio (10\%) por 10 minutos e lavadas em 


\section{ACTA \\ AMAZONICA}

água destilada. Os explantes foram inoculados em meio MS com suplementação de sacarose a 3\% e ágar a $0,7 \%$. Este experimento contou com 4 tratamentos e 10 repetições.

No segundo experimento foi combinado Agrimicina com o antibiótico Ampicilina. O pré-tratamento consistiu na imersão por $48 \mathrm{~h}$ em Benomyl $(400 \mathrm{mg} / \mathrm{l})$. Em seguida, o material recebeu tratamento com bomba a vácuo em solução combinada entre Agrimicina $(0,300,500 \mathrm{mg} /)$ e Ampicilina $(0$, $300,500 \mathrm{mg} /$ ). Posteriormente, os explantes passaram pelo processo normal de desinfestação, com etanol (70\%) com Tween-20 por 90 segundos e hipoclorito de sódio (20\% e 2\% de cloro ativo) por 10 minutos. O meio adotado foi o MS com suplementação de sacarose a $3 \%$ e ágar a $0,7 \%$. Foram testados 7 tratamentos com 10 repetições.

Os dados foram submetidos a análise de variância e comparação de médias dos tratamentos pelo teste de Tukey.

\section{RESULTADOS E DISCUSSÕES}

A análise de variância revelou que existem diferenças significativas entre os tratamentos para a porcentagem de germinação dos embriôes e sobrevivência (Tabela 1). Observa-se que o tratamento 3, não apresentou contaminação fúngica e bacteriana, resultando na maior porcentagem de sobrevivência (100\%) dos embriões inoculados após 45 dias. Os tratamentos 4 , 6,7 e 10 apesar da contaminação por fungos (19a 58\%) ebactérias (0 a 3\%) apresentaram as maiores porcentagens de germinação dos embriões (34 a 53\%). A germinação de embrióes assépticos in vitro se constitui um fato promissor para propagação desta espécie. Considerando que a assepsia e o manuseio das sementes durante a retirada dos embriões podem ser otimizados, a contaminação fúngica e bacteriana poderá ser reduzida, aumentando a probabilidade da propagação in vitro do pau-rosa.
O controle da oxidação em explantes cultivados in vitro é de fundamental importância para o sucesso da cultura. As diferenças significativas entre as médias de porcentagem de oxidação ( $5 \%$ Tukey), revelam que os tratamentos $4 \mathrm{e} 12$ foram mais eficientes para reduzir a oxidação dos embriões pela menor liberação de fenóis no momento da inoculação (Tabela 1). Devese considerar que $o$ alto teor de substâncias fenólicas liberadas pelos embriões de pau-rosa, pode estar associado com a habilidade técnica e o tempo no isolamento de embrióes no momento da excisão. Estudos revelam que a oxidação fenólica foi limitante no estabelecimento da cultura de embriões imaturos de manga (Mangifera indica), recomendando-se a troca constante de meio de cultura e o uso de antioxidantes (Rodriguez, 1989). Outros estudos indicam que a manutenção das culturas no escuro por 7 a 15 dias reduz a oxidação fenólica de embriões e endosperma de andiroba (Carapa guianensis) (Amaral et al., 1997).

Após 45 dias, foi observado que existem diferenças significativas entre as médias de porcentagem de germinação dos embriões de pau-rosa (Teste de Duncan). O tratamento 4, com 5\% de sacarose, apresentou 53\% de germinação. Foi observado primórdios foliares e a formação de radícula em explantes dos tratamentos $3,4,5,6,7,8$ e 9 , evidenciando que as concentrações de sacarose e água de côco favoreceram o estabelecimento e desenvolvimentos dos embrióes de paurosa (Tabela 1).

Foram testados diferentes tipos de assepsia dos embrióes de pau-rosa neste estudo. Embriões de pau-rosa (Aniba rosaeodora) submetidos à temperatura de $40^{\circ} \mathrm{C}$ por 30 minutos e assepsia com hipoclorito de sódio por 30 minutos apresentaram 95\% de embrióes assépticos (Souza et al., 1997). Embriões de Cedrela odorata, apresentaram 100\% de germinação com assepsia em hipoclorito de sódio (2\%) e adição de $1 \%$ de

Tabela 1 - Médias da porcentagem de oxidação, sobrevivência e germinação dos embriões de pau-rosa (Aniba rosaeodora Ducke) após 45 dias.

\begin{tabular}{|c|c|c|c|c|c|c|c|}
\hline \multirow[t]{2}{*}{ Tratamento } & \multirow[t]{2}{*}{$\begin{array}{c}\text { Sacarose } \\
(\%)\end{array}$} & \multirow[t]{2}{*}{$\begin{array}{c}\text { Água de } \\
\text { côco(mg/l) }\end{array}$} & \multicolumn{2}{|c|}{$\begin{array}{c}\text { Contaminação } \\
(\%)\end{array}$} & \multirow[t]{2}{*}{$\begin{array}{c}\text { Oxidação } \\
(\%)\end{array}$} & \multirow[t]{2}{*}{$\begin{array}{c}\text { Sobrevivência } \\
\text { (\%) }\end{array}$} & \multirow[t]{2}{*}{$\begin{array}{c}\text { Germinação } \\
\text { (\%) }\end{array}$} \\
\hline & & & Fungo & Bactéria & & & \\
\hline 1 & 0 & 0 & 28 & 0 & $2 a b c$ & $72 \mathrm{abc}$ & $8 c$ \\
\hline 2 & 0 & 10 & 10 & 0 & $3 a b c$ & $90 \mathrm{ab}$ & $9 c$ \\
\hline 3 & 0 & 20 & 0 & 0 & $4 \mathrm{abc}$ & $100 \mathrm{a}$ & $25 \mathrm{bc}$ \\
\hline 4 & 5 & 0 & 19 & 3 & $0 \mathrm{c}$ & $71 \mathrm{abc}$ & $53 a$ \\
\hline 5 & 5 & 10 & 30 & 4 & $1 \mathrm{bc}$ & $70 \mathrm{abc}$ & $25 \mathrm{bc}$ \\
\hline 6 & 5 & 20 & 20 & 0 & $7 \mathrm{a}$ & $80 \mathrm{ab}$ & $48 \mathrm{ab}$ \\
\hline 7 & 10 & 0 & 58 & 3 & $1 \mathrm{bc}$ & $42 \mathrm{bc}$ & $42 a b$ \\
\hline 8 & 10 & 10 & 38 & 3 & $6 a b$ & $62 \mathrm{abc}$ & $18 \mathrm{bc}$ \\
\hline 9 & 10 & 20 & 69 & 5 & $1 \mathrm{bc}$ & 31 bc & $18 \mathrm{bc}$ \\
\hline 10 & 15 & 0 & 19 & 0 & $2 a b c$ & $81 \mathrm{ab}$ & $34 a b$ \\
\hline 11 & 15 & 10 & 59 & 6 & $4 a b c$ & $41 \mathrm{bc}$ & $19 \mathrm{bc}$ \\
\hline 12 & 15 & 20 & 89 & 7 & $0 \mathrm{c}$ & $11 \mathrm{c}$ & $10 \mathrm{c}$ \\
\hline
\end{tabular}

* Médias seguidas de mesma letra não diferem entre si pelo teste de Tukey a $5 \%$ de probabilidade. 
sacarose em meio de cultura (Gomes et al. 1997). Embriões imaturos de Coffea sp., a utilização de $0,5 \%$ de bicloreto de mercúrio proporcionou $100 \%$ de embriões assépticos (Andrade, 1998).

Gemas apicais da rebrota de mudas cultivadas na casa de vegetação quando cultivadas in vitro apresentaram elevadas contaminações fúngicas e por bactérias endógenas (Tabela 2). A menor porcentagem de contaminação foi obtida pelo tratamento 2 , com $33 \%$ de contaminação fúngica e $29 \%$ de contaminação bacteriana mediante a imersão por 1 hora em solução contendo Agrimicinaa $300 \mathrm{mgl}$, evidenciandoa eficácia parcial do Sulfato de Estreptomicina parao estabelecimento in vitro dos explantes (Tabela 2). Observa-se que ouso de maiores concentrações de agrimicina $(400 \mathrm{e} 500 \mathrm{mg} /$ 1) reduziu de maneira significativa a contaminação por bactérias. Entretanto, é necessário novos testes envolvendo maiores concentrações de antibiótico e tempos de exposição (Tabela 2).

Aaplicação quinzenal de fungicidas nas mudas na casa de vegetação e a coleta dos explantes das brotações mais recentes contribuíram para diminuir a incidência de bactérias endógenas em explantes cultivados in vitro. Estudos indicam que o material proveniente de mudas mantidas na casa de vegetação são ideais para o cultivo in vitro, por serem menos propensas a contaminações (Wiechetech, 1990). Neste estudo, a dificuldade da esterilização dos brotos apicais e axilares tem sido uma barreira para cultura in vitro do pau-rosa.

O uso de antibióticos, como a Rifampicina, em meio de cultura visando controlar a contaminação por bactérias endógenas foi utilizado em gemas laterais de mamoeiro (Cornélio \& Haridasan, 1995). Resultados similares em Canela sassafras foram observados por Wang et al. (1991).

Na Tabela 3, observa-se o efeito da combinação dos tratamentos com Agrimicina e Ampicilina visando o controle da contaminação por fungos e bactérias dos explantes da rebrota das mudas, mediante o emprego de vácuo na desinfestação dos explantes. As menores porcentagens de contaminação fúngica ( $40 \%$ ) foram obtidas nos tratamentos 3 e 5, pela combinação de Agrimicina e Ampicilina, ambas na concentração de $300 \mathrm{mg} 1$, embora não tenha diferido estatisticamente de 2, 4,6 7 . A maior porcentagem de sobrevivência foi observada no tratamento 5 .

Neste estudo não foi possível a identificação das bactérias endógenas desta espécie, o que dificultou o uso de um antibiótico específico para a eliminação das bactérias. A combinação de Agrimicina e Ampicilina e as possíveis falhas na assepsia devido á elevada contaminação por fungos, contribuíram para a baixa porcentagem de sobrevivência in vitro dos explantes da rebrota de mudas de pau-rosa (Tabela 3).
Tabela 2 - Efeito da concentração de Agrimicina na desinfestação de rebrota de paurosa cultivadas in vitro.

\begin{tabular}{|c|c|c|c|c|c|c|}
\hline \multirow[t]{2}{*}{ Tratamentos } & \multirow[t]{2}{*}{$\begin{array}{c}\text { Agrimicina } \\
(\mathrm{mg} / \mathrm{l})\end{array}$} & \multirow[t]{2}{*}{$\begin{array}{c}\text { Tempo } \\
\text { (minutos) }\end{array}$} & \multicolumn{2}{|c|}{$\begin{array}{c}\text { Contaminação } \\
(\%)\end{array}$} & \multirow[t]{2}{*}{$\begin{array}{c}\text { Oxidação } \\
(\%)\end{array}$} & \multirow[t]{2}{*}{$\begin{array}{c}\text { Sobrevivência } \\
\text { (\%) }\end{array}$} \\
\hline & & & Fungo & Bactéria & & \\
\hline 1 & 0 & 60 & $80 a$ & $87 a$ & $6 a$ & $0 \mathrm{a}$ \\
\hline 2 & 300 & 60 & $33 \mathrm{~b}$ & $29 \mathrm{~b}$ & $3 a$ & $48 \mathrm{c}$ \\
\hline 3 & 400 & 60 & $76 a$ & $44 \mathrm{~b}$ & $2 a$ & $13 a b$ \\
\hline 4 & 500 & 60 & $44 \mathrm{ab}$ & $26 \mathrm{~b}$ & $2 a$ & $51 \mathrm{c}$ \\
\hline
\end{tabular}

Tabela 3 - Efeito da concentração de Agrimicina e Ampicilina na desinfestação de rebrota de pau-rosa.

\begin{tabular}{|c|c|c|c|c|c|c|}
\hline \multirow{3}{*}{ Tratamentos } & \multirow{3}{*}{$\begin{array}{c}\text { Agrimicina } \\
(\mathrm{mg} / \mathrm{l})\end{array}$} & \multirow{3}{*}{$\begin{array}{c}\text { Ampicilina } \\
(\mathrm{mg} / \mathrm{l})\end{array}$} & \multirow{2}{*}{\multicolumn{2}{|c|}{$\begin{array}{c}\text { Contaminação } \\
(\%)\end{array}$}} & \multicolumn{2}{|c|}{ Oxidação Sobrevivência } \\
\hline & & & & & (\%) & (\%) \\
\hline & & & Fungo & Bactéria & & \\
\hline 1 & 0 & 0 & $100 \mathrm{a}$ & $50 \mathrm{a}$ & $80 \mathrm{a}$ & $0 \mathrm{a}$ \\
\hline 2 & 300 & 0 & $56 a b$ & $50 \mathrm{a}$ & $68 \mathrm{a}$ & $11 \mathrm{ab}$ \\
\hline 3 & 300 & 300 & $40 \mathrm{~b}$ & $50 a$ & $73 a$ & $18 \mathrm{~b}$ \\
\hline 4 & 300 & 500 & $59 a b$ & $20 a$ & 73 a & $12 a b$ \\
\hline 5 & 500 & 0 & $40 \mathrm{~b}$ & 30 a & $82 \mathrm{a}$ & $25 \mathrm{~b}$ \\
\hline 6 & 500 & 300 & $47 \mathrm{ab}$ & $40 \mathrm{a}$ & $74 \mathrm{a}$ & $9 \mathrm{ab}$ \\
\hline 7 & 500 & 500 & $50 \mathrm{ab}$ & $50 \mathrm{a}$ & $78 \mathrm{a}$ & $8 a b$ \\
\hline
\end{tabular}

das de mesma letra não diferem entre si pelo teste de Tukey

A toxidez de mais de vinte tipos de antibióticos foi examinada em culturas de protoplastos de Nicotiana plumbaginifolia, verificando que a ação dos antibióticos a base de Ampicilina, Estreptomicina, Rifampicina, possuem amplo espectro de ação (Pollock et.al. 1983).

A utillização de antibióticos é necessária no controle da contaminação por bactérias endógenas presentes nos explantes de pau-rosa. A utilização do vácuo no processo de desinfestação, permite o aumento da dilatação dos poros do explante e auxilia na penetração da solução (Pasqual et al., 1998). Entretanto, os resultados indicam que a média de sobrevivência do material inoculado a vácuo ainda é baixa (Tabela 3), quando comparada ao processo tradicional de desinfestação (Tabela 2).

No entanto, quando comparado com a utilização de ápicese segmentos nodais, oápice proveniente de rebrota, oferece melhores condições de isolamento para a organogênese direta in vitro.

\section{CONCLUSÕES}

De acordo com os resultados obtidos neste trabalho, podese concluir que:

1) As rebrotas tratadas com Sulfato de Estreptomicina (Agrimicina) na concentração de $300 \mathrm{mg} /$ indicaram 33\% de contaminação fúngica e $29 \%$ de contaminação bacteriana, com $48 \%$ de sobrevivência.

2) A menor incidência por bactérias endógenas em explantes de rebrota das mudas está associada à época de 
coleta e ao tipo de explante empregado e diminuiu, à medida que, brotações mais recentes foram utilizadas.

\section{BIBLIOGRAFIA CITADA}

Alencar, J. da C.; Araújo, V. C. de. 1980. Comportamento de espécies florestais amazônicas quanto à luminosidade. Acta amazonica, Manaus: INPA. 10(8): 435-444.

Amaral, S. A.; Silva, A. T. A.; Mota, M. G. C.; Vieira, I. M. S. 1997. Uso de tratamentos como antioxidantes de explantes (embrião, endosperma) de andiroba (Carapa guianensis Aubl.). In: Seminário de Iniciação Científica da FCAP,7.; Seminário de Iniciação Científica da Embrapa Amazônia Oriental, 1. Resumos. Belém: FCAP. p. 122-124.

Andrade, L. M. C. O. 1998. Otimização de técnicas de cultura de tecidos para o cafeeiro. Lavras: UFLA. 86p. Dissertação de mestrado.

Araújo, V. C. de. 1967. Sobre a germinação de Aniba (Lauraceae). I. A. duckei Kostermans (Pau-rosa itaúba). Botânica. Manaus: Inpa, 23. $21 \mathrm{pp}$.

Cestari, A. N.1975. Cultura de tecidos . Ciência e cultura, 27(10):1056-1069.

Cornélio, I. N.; Haridasan, P. 1995. Desinfestação de gemas laterais de mamoeiro (Carica papaya L.) provenientes de vários locais do Distrito Federal. In: V Congresso Brasileiro de Fisiologia Vegetal. Resumos. Lavras: UFLA. p. 136.

FAO.1993. Ex situ storage of seeds, pollen and in vitro cultures of perennial woody plant species. v.113. $83 \mathrm{pp}$.

Gomes, A. P. do R.; Lameira, O. A.; Lopes, S. da C.; Menezes, I.C.; Leão, N. V.M. 1997. Germinação de embriões de cedro (Cedrela odorata) submetidos a diferentes concentrações de sacarose em relação a luminosidade. In: Seminário de Iniciação Científica da FCAP,7.; Seminário de Iniciação Científica da Embrapa Amazônia Oriental, 1. Resumos. Belém: FCAP. p.275-276.

Grattapaglia, D.; Machado, M. A. 1998. Micropropagação. In: Torres, A.C.; Caldas, L.S. Técnicas e aplicações da cultura de tecidos de plantas. Brasília: EMBRAPA/CNPH. p.100-161.

Hartman, H. T.; Kester, D. E.; Davies JR, F. T. D. 1990. Plant propagation: principles and practices. Prentice-Hall/ Englewood Cliffs, New Jersey. 5 ed. p. 459-521.

Henao, L. M. M. 1991. Cultivo de tejidos vegetales. Medelin: Universidad Nacional de Colômbia. 77p.

Hu, C. Y.; Ferreira, A. G. 1998. Cultura de embriões. In: Torres, A. C.; Caldas, L. S. Técnicas e aplicações da cultura de tecidos de plantas. Brasília: Embrapa/CNPH. p.371-393.

Murashige, T.; Skoog, F. 1962. A revised medium for rapid growth and bio-assays with tobacco tissue culture. Physiologia Plantarum, 15:473-497.

Ohashi, S. T.; Rosa, L. S.; Santana, J. A. 1995. Diagnóstico Florestal do Pau-rosa (Aniba rosaeodora Ducke) no Brasil. Funatura/ITTO.
Pasqual, M.; Pinto, J. E. B. P. 1988. Cultura de embriões. Notícias da Associação Brasileira de Cultura de Tecidos de Plantas, Brasília, v.9. p. 2-12.

Pasqual, M.; Ramos, J. D.; Hoffman, A.; Carvalho, G. R. 1998. Cultura de tecidos vegetais: tecnologia e aplicações - meios de cultura. Lavras: UFLA/FAEPE. 127 p.il.

Pasqual, M.; Hoffmann, A.; Ramos, J.D. 1998. Cultura de tecidos vegetais: tecnologia e aplicações - introdução: fundamentos básicos. Lavras: UFLA/ FAEPE. 159 p.il.

Pierik, R.L.M. 1997. In vitro Culture of Higher Plants. Netherlands: Kluwer Academic Publishers. 348 p.

Pollock, K.; Barfield, D.G.; Shields, R. 1983. The toxicity of antibiotics to plant cell cultures. Plant cell reports, 2: 36-39.

Ribeiro, V. G. R.; Paqual, M.; Ramos, J. D.; Júnior, A. F. O.; Carvalho, G. R. 1997. Influência do pH e do ágar sobre o cultivo in vitro de embrióes de laranjeira-pêra. Pesq. agropec. bras., Brasília: 32(11): 1147-1152.

Roca, W. M.; Mroginski, L. A. 1991. Cultivo de tejidos en la agricultura: Fundamentos e aplicações. Cali: CIAT. 970 p.

Rodriguez, A. P. M. 1989. Viabilidade do uso de diferentes explantes e variedades de manga (Mangifera indica L.) em cultura de tecido. Piracicaba: ESALQ. 100pp. (Dissertação de mestrado)

Rosa, L.S.; Ohashi, S. T.; Santana, J. A. S.; Oliveira, F. A. 1993. Estágio atual de conhecimento sobre a formação de mudas de pau-rosa (Aniba rosaeodora Ducke). In: $1^{\circ}$ Congresso Florestal Brasileiro. Anais. Curitiba: SBS-SBEF. p. 761.

Sampaio, P. T. B. 1988. Propagação vegetativa do pau-rosa (Aniba rosaeodora Ducke) pelo método da estaquia. Manaus: INPA. 112pp. Dissertação de mestrado.

Sampaio, P. T. B.; Vieira, G.; Gomes, L. A.; Leite, A.; Quisen, R. 2000. Regeneração natural com propágulos para produção de mudas de pau-rosa (Aniba rosaeodora Ducke) em viveiro. In: Congresso e Exposição Internacional sobre Florestas (6: 2000: Porto Seguro, BA). Rio de Janeiro: Instituto Ambiental Biosfera. p. 177.

Souza, K. S. de ; Nunes, H. da C. B.; Silva, S. P. G. da; Vieira, I. M. S.; Mota, M.G. da C. 1997. Produção in vitro de plântulas de pau-rosa (Aniba rosaeodora). In: Seminário de Iniciação Científica da FCAP,7.; Seminário de Iniciação Científica da Embrapa Amazônia Oriental, 1. Resumos. Belém: FCAP. p.371-373.

Wang, P. J.; Hu, C. Y.; Chen, M. H. 1991. In: Bajaj, Y. P.S. 1991. Biotechnology in Agriculture and Forestry. Berlin: SpringerVerlag. p. 180-190.

Wiecheteck, M. S. S. 1990. Micropropagação de Eucalyptus viminalis Labill. a partir de material juvenil. Universidade Federal do Paraná. Curitiba. 92 pp. Dissertação de mestrado.

\section{RECEBIDO EM 04/10/2002 \\ ACEITO EM 29/12/2004}


